\title{
Melanoma of unknown primary: a case series
}

\author{
Claire Doyle $^{1} \cdot$ Barry O'Sullivan $^{2} \cdot$ Richard E Watchorn $^{1} \cdot$ Karen Eustace $^{1}$
}

Received: 4 February 2022 / Accepted: 8 February 2022 / Published online: 17 February 2022

(c) The Author(s), under exclusive licence to Royal Academy of Medicine in Ireland 2022

\section{Introduction}

Melanoma of unknown primary (MUP) was originally defined in 1963 by Dasgupta et al. as melanoma in the subcutaneous tissue, lymph nodes or visceral organs without the presence of cutaneous, ocular or mucosal primary [1]. The incidence of MUP is reported as between 1 and $8 \%$ of all melanomas [2]. The median age of presentation of MUP is between 40 and 50 years of age [3]. The male to female ratio is approximately 2:1 [4]. Sixty per cent of MUP presents in the lymph nodes - most frequently axillary lymph nodes, followed by cervical, inguinal and parotid lymph nodes [4]. Other sites of presentation include the subcutaneous tissue, lung, gastrointestinal tract and brain [5]. The American Joint Committee on Cancer (AJCC) classifies MUP presenting in a lymph node or subcutaneous tissue as stage three and MUP presenting within a visceral organ as stage four [4].

\section{Case series}

We report our experience in a single tertiary referral centre in Ireland. A database of all melanomas diagnosed between January 2018 and December 2021 was analysed for MUP. The total number of melanomas diagnosed in that timeframe was 298. Six patients were identified as having MUP with an incidence of $2.01 \%$. The demographics of the patients are detailed in Table 1. The median age was 63.3 years (range 45-84 years). Fifty per cent (3/6) were male. Fifty per cent (3/6) were female. $16.7 \%(1 / 6)$ presented with a primary dermal metastatic deposit, $66.67 \%$ (4/6) presented with isolated lymph node metastases, $0 \%(0 / 6)$ presented with visceral

Claire Doyle

doylec32@tcd.ie

1 Department of Dermatology, Beaumont Hospital, Beaumont Road, Dublin 9, Ireland

2 Department of Plastic Surgery, Beaumont Hospital, Beaumont Road, Dublin 9, Ireland metastases and $16.7 \%(1 / 6)$ presented with isolated brain metastases. The details of the speciality involvement with the patients are detailed in Table 2. One hundred per cent (6/6) were reviewed by dermatology and ophthalmology. Fifty per cent (3/6) were reviewed by ENT. 16.67\% (1/6) was referred to gynaecology. $16.67 \%$ (1/6) underwent endoscopic assessment for a primary gastrointestinal melanoma. No primary melanoma was identified in any of the patients by any specialist. One hundred per cent (6/6) underwent radiological evaluation via PET-CT to investigate for further metastases. One hundred per cent (6/6) underwent dedicated brain imaging via CT and MRI. One hundred per cent (6/6) underwent surgical resection of their MUP. One hundred per cent (6/6) were reviewed by medical oncology with $83.3 \%$ (5/6) commencing treatment with immunotherapy. There were no associated deaths to date. $83.3 \%$ (5/6) of the MUP was diagnosed in 2021. 16.67\% (1/6) was diagnosed in 2018.

\section{Discussion}

The aetiology of MUP is elusive. Possibilities proffered include an unrecognised melanoma, a previously excised melanoma that was misdiagnosed as benign, a primary melanoma that has completely regressed or the de novo malignant transformation of an aberrant melanocyte within a lymph node [4]. Recommendations for the evaluation of those with MUP include a full skin examination including subungual and mucosal surfaces by a dermatologist and an ocular examination to exclude primary melanoma. Patients should undergo imaging of the brain, thorax, abdomen and pelvis to assess disease burden. Referral to ENT can be considered to assess for mucosal melanoma of the nasopharynx. Gynaecology referral can be considered for those with inguinal lymphadenopathy [6]. Recent studies have shown the impact of the COVID-19 pandemic on the presentation of cutaneous melanoma including an increased Breslow thickness at the time of presentation when compared with a similar period pre-COVID-19 [7]. Our data indicates an increased rate of MUP presenting after the onset of the COVID-19 pandemic; 
Table 1 Demographics of patients

\begin{tabular}{lllllll}
\hline Age & Sex & $\begin{array}{l}\text { Year of } \\
\text { diagnosis }\end{array}$ & $\begin{array}{l}\text { Skin } \\
\text { metastases }\end{array}$ & $\begin{array}{l}\text { Lymph node } \\
\text { metastases }\end{array}$ & $\begin{array}{l}\text { Visceral } \\
\text { metastases }\end{array}$ & $\begin{array}{l}\text { Brain } \\
\text { metastases }\end{array}$ \\
\hline $\mathbf{7 8}$ & M & 2021 & Y & N & N & N \\
64 & M & 2021 & N & N & N & Y \\
45 & F & 2021 & N & Y & N & N \\
59 & M & 2021 & N & Y & N & N \\
84 & F & 2021 & N & Y & N & N \\
50 & F & 2018 & N & Y & N & N \\
\hline
\end{tabular}

Table 2 Investigations that MUP patients have undergone

\begin{tabular}{lllllll}
\hline Sex & Derm & Opth & ENT & Gynaecology & Radiology & $\begin{array}{l}\text { Endoscopic } \\
\text { evaluation }\end{array}$ \\
\hline M & Y & Y & Y & N/A & Y & Y \\
M & Y & Y & Y & N/A & Y & N \\
F & Y & Y & N & N & Y & N \\
M & Y & Y & Y & N/A & Y & N \\
F & Y & Y & N & Y & Y & N \\
F & $\mathrm{Y}$ & $\mathrm{Y}$ & N & N & Y & N \\
\hline
\end{tabular}

however, given the low number overall, no conclusions can be drawn. There is no current literature regarding the increased rate of MUP since the COVID-19 pandemic. Further studies may be required to investigate this observation. MUP is rare. Guidelines for the investigation of MUP are currently lacking and are needed to ensure the delivery of consistent evidence-based, care for patients.

\section{Declarations}

Competing interests The authors declare no competing interests.

\section{References}

1. Dasgupta T, Bowden L, Berg JW (1963) Malignant melanoma of unknown primary origin. Surg Gynecol Obstet 117:341-345

2. Cormier JN, Xing Y, Feng L, Huang X, Davidson L, Gershenwald JE, Lee JE, Mansfield PF, Ross MI (2006) Metastatic melanoma to lymph nodes in patients with unknown primary sites. 106(9):20122020. https://doi.org/10.1002/cncr.21835
3. Lee CC, Faries MB, Wanek LA, Morton DL (2008) Improved survival after lymphadenectomy for nodal metastasis from an unknown primary melanoma. J Clin Oncol 26:535-541

4. Kamposioras K, Pentheroudakis G, Pectasides D, Pavlidis N (2011) Malignant melanoma of unknown primary site. To make the long story short. A systematic review of the literature. Crit Rev Oncol Hematol 78(2):112-126. https://doi.org/10.1016/j. critrevonc.2010.04.007

5. Bae JM, Choi YY, Kim DS, Lee JH, Jang HS, Lee JH, Chung KY (2015) Metastatic melanomas of unknown primary show better prognosis than those of known primary: a systematic review and meta-analysis of observational studies. J Am Acad Dermatol 72(1):59-70. https://doi.org/10.1016/j.jaad.2014.09.029

6. Anbari KK, Schuchter LM, Bucky LP et al (1997) Melanoma of unknown primary site: presentation, treatment, and prognosisa single institution study. University of Pennsylvania Pigmented Lesion Study Group. Cancer 79:1816-1821

7. Ricci F, Fania L, Paradisi A, Di Lella G, Pallotta S, Sobrino L, Panebianco A, Annessi G, Abeni D (2020) Delayed melanoma diagnosis in the COVID-19 era: increased Breslow thickness in primary melanomas seen after the COVID-19 lockdown. J Eur Acad Dermatol Venereol 34(12):e778-e779. https://doi.org/10.1111/jdv. 16874. Epub 2020 Sep 1. PMID:32780876; PMCID:PMC7436601.

Publisher's Note Springer Nature remains neutral with regard to jurisdictional claims in published maps and institutional affiliations. 